\title{
Poverty and common mental disorders in India: the inseparable twins
}

\author{
Shyamkumar Sriram*
}

Department of Health Services Policy and Management, University of South Carolina, Columbia, South Carolina, USA

Received: 09 July 2018

Revised: 10 August 2018

Accepted: 11 August 2018

\section{*Correspondence:}

Dr. Shyamkumar Sriram,

E-mail: shyam.silverhawk@gmail.com

Copyright: (c) the author(s), publisher and licensee Medip Academy. This is an open-access article distributed under the terms of the Creative Commons Attribution Non-Commercial License, which permits unrestricted non-commercial use, distribution, and reproduction in any medium, provided the original work is properly cited.

\section{ABSTRACT}

CMDs are a significant cause of morbidity and disability. A large proportion of the population of India lives below the poverty line. This policy report aims to contribute to India's CMD prevention strategy by reviewing the relationship between CMDs and poverty. While more Indian studies are needed, this review identifies access barriers and social security insufficiencies and recommends measures to address them.

Keywords: Common mental disorders, Poverty, Government of India, National mental health program

\section{INTRODUCTION}

Home to over $17 \%$ of the world's population, India is a poor country with 1.24 billion people. ${ }^{1,2}$ Nearly $42 \%$ of the population of India lives below the poverty line, and $35 \%$ lives on less than $\$ 1$ per day. ${ }^{3-5}$ In addition to high rates of poverty, there are wide disparities in the distribution of wealth and health between the rich and the poor. Important indicators, such as the infant mortality rate (IMR) and having an institutional delivery, highlight these wide disparities. Among the poorest wealth quintile in India, the IMR is near 82 per 1,000 live births, yet only 34 infants in 1,000 live births die in the richest quintile, where pregnant women are six times more likely to deliver in an institution. ${ }^{6-8}$ The private sector, the largest segment of the country, accounts for $58 \%$ of India's hospitals and $81 \%$ of its doctors. ${ }^{9}$ The World Bank report clearly shows that India's OOP health expenditure, which is $89.2 \%$, is a significant barrier to healthcare utilization. ${ }^{10}$ Due to the lack of financial protection, approximately $20-28 \%$ of diseases in India remain untreated. ${ }^{11}$ Nearly 39 million people in India become impoverished every year due to high OOP health expenditures, and only $11 \%$ of India's population is protected by any form of health insurance. ${ }^{12-16}$ India is undergoing a period of epidemiological transition with $53 \%$ of deaths and $44 \%$ of DALYs lost attributable to non-communicable diseases including mental health conditions. $^{17}$

\section{RATIONALE}

Mental health problems are a silent epidemic affecting $13.7 \%$ of the people in India and contributing $31 \%$ of years lived with a disability. ${ }^{18-20}$ In India, mental, neurological, and substance abuse disorders increased by about 44\% between 1990 and 2013, and they are projected to increase by another $23 \%$ by $2025 .^{21}$ CMDs include depression and anxiety disorders that are classified in ICD-10 as "neurotic, stress-related, somatoform and mood disorders." 22 Some studies showed that the prevalence of CMDs was around $46.5 \%$ and the observed incidence of CMD was around $1.8 \%$ during a 12 -month period. ${ }^{23,24}$ Evidence from multiple studies in India identifies poverty as an important risk factor for CMDs. ${ }^{23-33}$ Systematic reviews showed that around $79 \%$ of studies showed positive associations between poverty and CMDs. ${ }^{27}$ Depression and emotional distress that manifest as somatic symptoms are strongly associated 
with poverty. ${ }^{34-37}$ However, the relation between CMDs and poverty is symbiotic and highly complex..$^{29,38}$ In addition to a number of associated health problems, CMDs have also been linked to lower economic productivity and high healthcare expenditures. ${ }^{27}$ Despite the high disease burden of CMDs and the established bidirectional relationship between poverty and CMDs, India's programs and interventions to address them are only rudimentary.

\section{AIMS}

- To identify the programs and interventions currently in place to address CMDs and poverty in India.

- To provide appropriate recommendations to the Government of India (GOI) regarding the programs/policies and interventions to be undertaken for early detection and treatment of CMDs and to address the underlying determinant of poverty.

\section{FINDINGS}

The National Mental Health Program mainly focused on severe mental disorders, but CMDs were not prioritized. ${ }^{39}$ Even after mental health was prioritized under the GOI's Twelfth Five-Year Plan, no specific plans for addressing CMDs and poverty were established. ${ }^{40}$ Access to healthcare facilities and financial protection mechanisms are necessary to dismantle poverty and treat CMDs. Access is affected by the lack of mental health workers and financial barriers. India has only 3500 psychiatrists (75\% of which are located in urban areas), and needs 9000 psychiatric nurses and 1600 social workers. ${ }^{40}$ The Medical Council of India is taking steps to increase the mental health manpower, but those steps are in nascent phases. ${ }^{40}$ Most CMDs could be treated as outpatients, but the National Health Insurance Program for the indigent, Rashtriya Swasthiya Bima Yojana (RSBY), provides financial coverage only for hospitalizations and does not cover any outpatient services. ${ }^{41}$ Given the high OOP healthcare costs related to CMDs, this causes significant access barriers. Many psychological and pharmacological interventions to reduce CMDs have been proven to be effective and cost-effective, but they still have not been adopted by national policy-makers. ${ }^{26}$ Poverty alleviation through the provision of micro-credit using self-help groups are done in some parts of India. ${ }^{42,43}$ These microcredit activities improve the mental health condition of women since they feel better because they are able to contribute to the financial status of the household. ${ }^{44}$ However, there are no such nationwide programs of the GOI, and no such measures are provided for men. No interventions target the negative synergy caused by poverty, lack of education, and CMDs. ${ }^{26}$

\section{RECOMMENDATIONS}

\section{Lay health counsellors}

PHC physicians in the public and private sectors serve the majority of the population. ${ }^{45}$ Recognition of CMDs by PHC physicians is very low. ${ }^{46}$ Evidence shows that training PHC physicians and lay health workers for early diagnosis of CMDs has better health outcomes for patients. ${ }^{47,48}$ The creation of a cadre of lay health workers in all PHC facilities along with the mandatory training of all doctors and lay health workers for early detection, treatment initiation, and quick referral for CMDs should be implemented. Early detection and treatment initiation reduces the costs of treating complicated illnesses and prevents work days lost for the poor. However, given the limited resources available in India, hiring a new cadre of workers may be difficult.

\section{Mental health care integration}

With 23,391 PHC centres and 145,894 sub-centres, India has an extensive public health infrastructure. ${ }^{49,50}$ Integrating the treatment of CMDs into the routine PHC has good outcomes. ${ }^{51-54}$ The World Health Organization (WHO) recommends that effective mental healthcare can be provided at the PHC level if the country has a wellfunctioning $\mathrm{PHC}$ system. ${ }^{54} \mathrm{WHO}$ recommends that specialists supervise PHC physicians wherever possible. ${ }^{53,54}$ Since India has a good PHC infrastructure, the GOI should establish mental healthcare integration into PHCs. This should be complemented by an increase in the residency options for psychiatry to increase the number of specialists to treat advanced cases and to supervise the PHC physicians, which will be expensive for the GOI to implement.

\section{Poverty alleviation measures}

Poverty has a direct effect on the development of CMDs. ${ }^{31}$ The Twelfth Five-Year Plan highlighted the need for the provision of social support to the mentally ill. $^{40}$ The GOI has a number of poverty reduction programs focussed on specific populations. ${ }^{55}$ However, no specific social programs are available for mentally ill people. The GOI should establish a national agency that offers economic and social assistance for the mentally ill and provides financial support for poor people to prevent the development of CMDs. Also, RSBY does not cover psychiatric outpatient visits. ${ }^{41}$ The recommendation to cover outpatient visits under RSBY will be made to the GOI. It will be expensive to implement the RSBY expansion and poverty alleviation measures, but ultimately these measures will save money in the long run.

\section{LIMITATIONS}

To advise the GOI, this report used published studies on CMDs and poverty, most of which focused on mental illness generally and not specifically on CMDs. Indian studies are very limited, and studies from different parts of the world may have problems when they are applied to the Indian settings. Only literature in English was used for the report. More credible India-based studies are needed. The recommendations were based on studies done in smaller parts of India and abroad. The 
applicability of the findings of the studies done with limited samples to the country as a whole is debatable.

\section{CONCLUSION}

India has a large population, around half of which is poor. With the high prevalence and incidence of CMDs and the established bi-directional relationship between mental health and poverty, the need to tackle both factors at the same time is vital. CMDs have the potential to affect workers' health and productivity, and unaddressed poverty leads to CMDs. It is important to implement the recommended measures since they aim at tackling both problems concurrently. With high levels of poverty, high OOP costs of private healthcare expenditures, low public health expenditures, poor facilities, and shortage of manpower for mental healthcare, the GOI should allocate more resources to improving access to mental health and take appropriate poverty alleviation measures. Improved mental healthcare will save costs and result in better economic gains and a healthier population. In India, mental health is not prioritized in the community and the family, thus it is the role of the government to make it a priority. Helping people with mental illness is vital for protecting human rights. The GOI is the guardian of the health of its citizens, thus it is the duty of the government to acknowledge and take appropriate steps to protect the mental health of its population. Thus political commitment is necessary to implement the recommendations proposed by this policy report.

\section{Funding: No funding sources}

Conflict of interest: None declared

Ethical approval: Not required

\section{REFERENCES}

1. Population Census 2011. Office of the Registrar General \& Census Commissioner, Ministry of Home Affairs, Government of India. Available at: http://censusindia.gov.in/. Accessed on 17 March 2018.

2. Registrar General and Census Commissioner. Population Projections for India and States 20012026, Report of the Technical Group on Population Projections Constituted by National Population Commission 2006. Available at: https://www. educationforallinindia.com/Population_Projection_ Report_2006.pdf Accessed on 19 March 2018.

3. Fuel for Life. Household Energy and Health. World Health Organization. Available at: http://apps.who. int/iris/bitstream/handle/10665/43421/92415631 68_eng.pdf?sequence $=1$. Accessed on $16 \mathrm{March}$ 2018.

4. Chen S, Ravallion M. The developing world is poorer than we thought, but no less successful in the fight against poverty. World Bank Policy Research Working Paper Series 4703. Washington DC: World Bank 2008. Available at: http://siteresources. worldbank.org/DEC/Resources/Developingworldisp oorerQJE.pdf Accessed on 8 March 2018.
5. Bhide S, Mehta AK. Chronic Poverty in Rural India: issues and findings from panel data. Journal of Human Development. 2004;5(2):195-209.

6. International Institute for Population Sciences. Mumbai, India: International Institute for Population Sciences; 2007. National Family Health Survey (NFHS-3), 2005-06: India. Available at: https://dhsprogram.com/pubs/pdf/ frind3/frind3vollandvol2.pdf Accessed on 30 March 2018.

7. Balarajan Y, Selvaraj S, Subramanian SV. Health care and equity in India. Lancet. 2011;377(9764):505-15.

8. Sen G, Iyer A, George A. Structural reforms and health equity: a comparison of NSS surveys, 198687 and 1995-96. Econ Polit Wkly. 2002;37:134252.

9. Thadani KB. Public Private Partnership in the Health Sector: Boon or Bane. Procedia - Social and Behavioral Sciences. 2014;157:307-16.

10. World Bank. Out of Pocket Health Expenditures. Available at: https://data.worldbank.org/indicator/ SH.XPD.OOPC.ZS. Accessed on 21 February 2018.

11. Ministry of Health and Family Welfare, Government of India. Select health parameters: a comparative analysis across the National Sample Survey Organization 42nd, 52nd, and 60th Rounds. 2007. Available at: https://ruralindiaonline.org/ resources/select-health-parameters-a-comparativeanalysis-across-the-national-sample-surveyorganization-nsso-42nd-52nd-and-60th-rounds/ Accessed on 11 March 2018.

12. Balarajan Y, Selvaraj S, Subramanian SV. Health care and equity in India. Lancet. 2011;377(9764):505-15.

13. Gupta I, Trivedi M. Health insurance: beyond a piecemeal approach. Econ Polit Wkly. 2006;41:2525-8.

14. Acharya A, Ranson K. Health care financing for the poor: community-based health insurance schemes in Gujarat. Econ Polit Wkly. 2005;40:4141-50.

15. Ellis RP, Alam M, Gupta I. Health insurance in India: prognosis and prospects. Econ Polit Wkly. 2000; 35: 207-17.

16. Ranson MK, Sinha T, Chatterjee M, Acharya A, Bhavsar A, Morris SS, et al. Making health insurance work for the poor: learning from the SelfEmployed Women's Association's (SEWA) community-based health insurance scheme in India. Social Sci Med. 2006;62(3):707-20.

17. Srinath Reddy K, Shah B, Varghese C, Ramadoss A. Responding to the threat of chronic diseases in India. Lancet. 2005;366(9498):1744-9.

18. Lozano R, Naghavi M, Foreman K, Lim S, Shibuya $\mathrm{K}$, Aboyans V, et al. Global and regional mortality from 235 causes of death for 20 age groups in 1990 and 2010: a systematic analysis for the Global Burden of Disease Study 2010. Lancet. 2012;380(9859):2095-128.

19. World Health Organization. Mental health and development: targeting people with mental health conditions as a vulnerable group. 2010. Available 
at:http://apps.who.int/iris/bitstream/handle/10665/44 257/9789241563949_eng.pdf?sequence=1\&isAllow ed=y. Accessed on 28 March 2018.

20. Vos T, Flaxman AD, Naghavi M, Lozano R, Michaud C, Ezzati M, et al. Years lived with disability (YLDs) for 1160 sequelae of 289 diseases and injuries 1990-2010: a systematic analysis for the Global Burden of Disease Study 2010. Lancet. 2012;380(9859):2163-96.

21. Charlson FJ, Baxter AJ, Cheng HG, Shidhaye R, Whiteford HA. The burden of mental, neurological, and substance use disorders in China and India: a systematic analysis of community representative epidemiological studies. Lancet. 2016;388(10042):376-89.

22. The ICD-10 classification of mental and behavioural disorders. Geneva: World Health Organziation; 1992. Available at: http://apps.who.int/iris/ bitstream/handle/10665/37958/9241544228_eng.pdf ;jsessionid=4F8B01234DC1421D9DCE722FF2218 7C9? sequence=8. Accessed on 20 February 2018.

23. Patel V, Kirkwood BR, Pednekar S, Weiss H, Mabey D. Risk factors for common mental disorders in women: Population-based longitudinal study. Br J Psychiatr. 2018;189(6):547-55.

24. Patel V, Araya R, de Lima M, Ludermir A, Todd C. Women, poverty and common mental disorders in four restructuring societies. Social Sci Med. 1999;49(11):1461-71.

25. Pathak N, Singh RN, Singh UP. Socio-economics of women's mental health in India. Indian J Health Wellbeing. 2017;8(11):1304-8.

26. Patel V, Kleinman A. Poverty and common mental disorders in developing countries. Bull World Health Organ. 2003;81(8):609-15.

27. Lund C, Breen A, Flisher AJ, Kakuma R, Corrigall J, Joska JA, et al. Poverty and common mental disorders in low and middle income countries: A systematic review. Social Sci Med. 2010;71(3):51728.

28. Patel V, Pereira J, Coutinho L, Fernandes R, Fernandes J, Mann A. Poverty, psychological disorder and disability in primary care attenders in Goa, India. $\mathrm{Br} \mathrm{J}$ Psychiatr: J Mental Sci. 1998;172:533-6.

29. Das J, Do QT, Friedman J, McKenzie D, Scott K. Mental health and poverty in developing countries: revisiting the relationship. Social Sci Med. 2007;65(3):467-80.

30. Weaver LJ, Hadley C. Moving beyond hunger and nutrition: a systematic review of the evidence linking food insecurity and mental health in developing countries. Ecol Food Nutr. 2009;48(4):263-84.

31. Kuruvilla A, Jacob KS. Poverty, social stress \& mental health. The Indian J Med Res. 2007;126(4):273-8.

32. Patel V, Burns JK, Dhingra M, Tarver L, Kohrt BA, Lund $\mathrm{C}$. Income inequality and depression: a systematic review and meta-analysis of the association and a scoping review of mechanisms. World psychiatry: official journal of the World Psychiatric Association (WPA). 2018;17(1):76-89.

33. Brinda EM, Rajkumar AP, Attermann J, Gerdtham UG, Enemark U, Jacob KS. Health, Social, and Economic Variables Associated with Depression Among Older People in Low and Middle Income Countries: World Health Organization Study on Global AGEing and Adult Health. J American Assoc Geriatric Psych. 2016;24(12):1196-208.

34. Mohindra KS, Haddad S, Narayana D. Can microcredit help improve the health of poor women? Some findings from a cross-sectional study in Kerala, India. Int J Equity Health. 2008;7:2.

35. Patel V, Chisholm D, Kirkwood BR, Mabey D. Prioritizing health problems in women in developing countries: comparing the financial burden of reproductive tract infections, anaemia and depressive disorders in a community survey in India. Trop Med Int Health. 2007;12(1):130-9.

36. Pereira B, Andrew G, Pednekar S, Pai R, Pelto P, Patel V. The explanatory models of depression in low income countries: listening to women in India. J Affective Dis. 2007;102(1-3):209-18.

37. Raguram R, Weiss MG, Channabasavanna SM, Devins GM. Stigma, depression, and somatization in South India. Am J Psychiatr. 1996;153(8):1043-9.

38. Lund C, De Silva M, Plagerson S, Cooper S, Chisholm D, Das J, et al. Poverty and mental disorders: breaking the cycle in low-income and middle-income countries. Lancet. 2011;378(9801):1502-14.

39. Sinha SK, Kaur J. National mental health programme: Manpower development scheme of eleventh five-year plan. Indian $\mathrm{J}$ Psychiatry. 2011;53(3):261-5.

40. Chatterjee P. Economic crisis highlights mental health issues in India; 2009: 1160-1161.

41. Karan A, Yip W, Mahal A. Extending health insurance to the poor in India: An impact evaluation of Rashtriya Swasthya Bima Yojana on out of pocket spending for healthcare. Social Sci Med. 2017;181:83-92.

42. Premchander S, Prameela V, Chidambaranathan M, Jeyaseelan L. Multiple Meanings of Money. How Women See Microfinance, Sage, New Delhi, India, 2009. Available at: https://books.google.com/ books/about/Multiple_Meanings_of_Money.html?id =89GGAwAAQBAJ. Accessed on 17 February 2018.

43. NABARD, Status of Micro-Finance in India-20072008, NABARD, Mumbai, India, 2008. Available at: https://www.nabard.org/auth/writereaddata/ ender/ 3107173636SMFI\%202007-08.pdf. Accessed on 28 February 2018.

44. Empowering women through self-help micro-credit programmes. Bulletin on Asia-Pacific Perspectives 2002/3. Available at: http://lessons.micro financelessons.com/lesson14/resources/empowering 
_women_SH_progs.pdf. Accessed on 26 March 2018.

45. Brugha R, Zwi A. Improving the quality of private sector delivery of public health services: challenges and strategies. Health Policy Planning. 1998;13(2):107-20.

46. Patel V. Recognition of common mental disorders in primary care in African countries: should "mental" be dropped? Lancet. 1996;347:742-4.

47. Patel V, Weiss HA, Chowdhary N, Naik S, Pednekar S, Chatterjee S, et al. Effectiveness of an intervention led by lay health counsellors for depressive and anxiety disorders in primary care in Goa, India (MANAS): a cluster randomised controlled trial. Lancet. 2010;376(9758):2086-95.

48. Shinde S, Andrew G, Bangash O, Cohen A, Kirkwood B, Patel V. The impact of a lay counselor led collaborative care intervention for common mental disorders in public and private primary care: a qualitative evaluation nested in the MANAS trial in Goa, India. Social Sci Med. 2013;88:48-55.

49. Indian Public Health Standards for Primary Health Centers; Guidelines (March 2006); Directorate General of Health Services, Ministry of Health and Family Welfare; Government of India. Available at: http://www.iapsmgc.org/ userfiles/4IPHS_for_PHC.pdf. Accessed on 21 March 2018.

50. Indian Public Health Standards for sub-centers; Guidelines (March 2006); Directorate General of Health Services; Ministry of Health and Family
Welfare; Government of India. Available at: http://www.iapsmgc.org/userfiles/ 3IPHS_for_SUBCENTRES.pdf. Accessed on 28 March 2018.

51. Chatterjee S, Chowdhary N, Pednekar S, Cohen A, Andrew G, Andrew G, et al. Integrating evidencebased treatments for common mental disorders in routine primary care: feasibility and acceptability of the MANAS intervention in Goa, India. WPA. 2008;7(1):39-46.

52. Funk M, Saraceno B, Drew N, Faydi E. Integrating mental health into primary healthcare. Mental Health Fam Med. 2008;5(1):5-8.

53. Davies $\mathrm{T}$, Lund $\mathrm{C}$. Integrating mental health care into primary care systems in low- and middleincome countries: lessons from PRIME and AFFIRM. Global Mental Health. 2017;4:e7.

54. World Health Organization. Integrating mental health into primary care: a global perspective. Available at: http://www.who.int/mental_health/ policy/services/integratingmhintoprimarycare/en/. Accessed on 8 March 2018.

55. Ravallion M. A Comparative Perspective On Poverty Reduction In Brazil, China And India: The World Bank; 2009:39.

Cite this article as: Sriram S. Poverty and common mental disorders in India: the inseparable twins. Int $\mathbf{J}$ Community Med Public Health 2018;5:4629-33. 